\title{
Thermal demand response model considering user's satisfaction with heat consumption under electrothermal coupling
}

\author{
Wang Zhenyu ${ }^{1,2}$, Zhang Jianhua ${ }^{3}$, Hu Chunlan ${ }^{3}$, Xu Lanlan $^{3}$, Han Yongjun ${ }^{3}$ \\ ${ }^{1}$ NARI GROUP CORPORATION/STATE GRID ELECTRIC POWER RESEARCH INSTITUTE, Nanjing 210000, China; \\ ${ }^{2}$ STATE GRID ELECTRIC POWER RESEARCH INSTITUTE WUHAN EFFICIENCY EVALUATION COMPANY LIMITED, \\ Wuhan 430074, China \\ ${ }^{3}$ State Grid Gansu Electric Power Company
}

\begin{abstract}
In recent years, the development of new energy has become a bottleneck. As a high-quality demand side response resource that can be flexibly dispatched, thermal load can be used to promote the consumption and utilization of new energy. Based on the theory of peak valley electricity price and power demand response mechanism, this paper designs a demand response model of thermal price type, which uses time-sharing heat price to guide users to use heat orderly on the heating side. The simulation results show that the reasonable setting of heat price and satisfaction constraints of different heating modes can effectively change the heating mode of the user side and alleviate the contradiction between the supply and demand of thermal power, reduce the heating cost and realize the economic operation of the system.
\end{abstract}

\section{Introduction}

In recent years, China's wind power, photovoltaic power generation and other new energy have developed rapidly, and the installed capacity has been expanding.However, due to the influence of small local consumption space, limited grid structure in some areas and imperfect market mechanism to promote the consumption and utilization of new energy, the problem of wind and light abandonment in "Three North" areas is serious. At the same time, the thermal load in the "Three North" areas shows the characteristics of high flexibility, fast response and large scale potential, which can be used as highquality power resources to absorb new energy in these areas.

Under the traditional power dispatching mode, due to the lack of effective mechanism and technical support, it is difficult for users to make full use of the flexible interaction potential of regional heating load. It is of great practical significance to establish a reasonable market mechanism, stimulate the enthusiasm of thermal load users to participate in the market, and further tap the value of thermal load response dispatching, which is of great practical significance to solve the problem of abandoning wind and light and promote the construction of domestic power market.

At home and abroad, preliminary exploratory research has been carried out on the flexible response capacity of thermal load and the potential of clean energy consumption. Reference [1-2] proposed a risk assessment method for thermal load using Monte Carlo method and verified it; reference [3] developed a risk assessment method considering thermal load based on graph theory and hydraulic calculation model. Literature

* Corresponding author:gaoyuanhd@163.com
[4-5] continuously improved the incentive policy of renewable energy, improved the mode of renewable energy participating in the electricity market, and improved the electricity market to adapt to the high proportion of new energy access.

In China, the comprehensive risk index is introduced in reference [6-7], and an improved risk assessment method for power system considering wind power error distribution is proposed. Reference [8] proposed an optimization model of integrated energy system for park microgrid considering the comprehensive demand response of multiple electric heating loads. Reference [910] proposed that heating load as adjustable load can be applied to optimal dispatching of thermal power plants participating in power market competition.

The existing literature focuses on the study of thermal load participating in clean energy consumption from the perspective of risk assessment, but there is no research on how to stimulate the enthusiasm of thermal load users to participate in the market through marketoriented means. Therefore, this paper designs a demand response model of thermal price type based on peak valley electricity price theory, and uses time-sharing heat price to guide users to use heat orderly on the heating side. The simulation results show that the reasonable setting of heat price and satisfaction constraints of different heating modes can effectively change the heating mode of the user side, promote the high proportion of new energy consumption, reduce the heating cost and realize the economic operation of the system. 


\section{Schedulability analysis of electric heating load and comprehensive demand response of electric heating}

In the park integrated energy system, with the deepening of electric thermal coupling, thermal demand response also has dispatching value, such as industrial heat load, heating load and so on, which have similar energy consumption characteristics with electric load. As flexible load, it has the potential to participate in demand response. The application of demand side response in power system has proved this point. With the development of integrated energy system, the coupling of different forms of energy in production, transmission and consumption is becoming stronger and stronger. Therefore, it is necessary to stimulate the enthusiasm of thermal load users to participate in the market by means of marketization, and further tap the value of thermal load response dispatch.

The following table shows the typical equipment classification of load side electric heating comprehensive demand response.

Table 1. Typical electric load response.

\begin{tabular}{|c|c|c|c|c|}
\hline $\begin{array}{l}\text { Response } \\
\text { type }\end{array}$ & $\begin{array}{c}\text { Response } \\
\text { device }\end{array}$ & $\begin{array}{l}\text { Energy } \\
\text { flow type }\end{array}$ & $\begin{array}{l}\text { Response } \\
\text { speed }\end{array}$ & $\begin{array}{l}\text { Application } \\
\text { scenarios }\end{array}$ \\
\hline \multirow{3}{*}{$\begin{array}{l}\text { Load } \\
\text { reduction }\end{array}$} & $\begin{array}{l}\text { Heating } \\
\text { load }\end{array}$ & $\begin{array}{l}\text { Electricity } \\
\text { / heat }\end{array}$ & fast & \multirow{3}{*}{$\begin{array}{l}\text { Large buildings } \\
\text { (intelligent } \\
\text { buildings / } \\
\text { residential } \\
\text { buildings) }\end{array}$} \\
\hline & heater & $\begin{array}{c}\text { Electricity } \\
\text { / heat }\end{array}$ & fast & \\
\hline & lighting & Electricity & fast & \\
\hline \multirow{3}{*}{$\begin{array}{l}\text { Load } \\
\text { transfer }\end{array}$} & $\begin{array}{l}\text { electric } \\
\text { vehicle }\end{array}$ & Electricity & fast & \multirow{3}{*}{$\begin{array}{c}\text { Park (Industrial } \\
\text { Park / electric } \\
\text { vehicle / } \\
\text { ecotourism / } \\
\text { Entertainment } \\
\text { Park / commercial } \\
\text { and residential } \\
\text { community) }\end{array}$} \\
\hline & $\begin{array}{l}\text { Energy } \\
\text { storage }\end{array}$ & $\begin{array}{c}\text { Electricity } \\
\text { / heat }\end{array}$ & fast & \\
\hline & $\begin{array}{l}\text { Industrial } \\
\text { heat load }\end{array}$ & Heat & fast & \\
\hline
\end{tabular}

According to the characteristics of users, thermal load can be divided into industrial heat load and civil heat load. The industrial heat load is fixed by thermal continuous trimming sequence, which can not be reduced, but can be transferred by proper overall translation. The reliability requirement of civil heat load is not very high, so the load can be increased or reduced appropriately, such as heating load. The user's perception of temperature is fuzzy. The concept of thermal demand response has not been reported in relevant literature. Based on this, according to different load characteristics, the transferable heat load is divided into price based thermal demand response, and the reduced heating load is defined as the thermal demand response based on thermal characteristics.

\section{Thermal demand response model considering customer satisfaction with heating mode}

\section{1 modeling of peak valley heat price elasticity matrix}

Thermal load and electricity also have commodity attributes. In demand side management of heating, the purpose of time-sharing heating price is to regulate the heat consumption behavior of heat users through price incentives. When facing the price signals of different time periods, users will reasonably adjust their own heating mode and time under the driving of interests.

The guidance of heat price will inevitably lead to the change of heat consumption mode, which will directly affect the heat consumption habits of heat users, and further affect their own satisfaction and acceptance of the new policy. In the previous studies, the thermal user's satisfaction with the heating mode was not considered in the response degree of the thermal users. Therefore, this paper takes into account the user's satisfaction with the thermal mode into the user response curve, defines the thermal mode satisfaction and modifies the thermal price elasticity matrix.

In the peak valley period, after the implementation of peak valley time-sharing heat price, users adjust their own heating mode. The heat consumption in each period can be described as follows:

$$
\left\{\begin{array}{l}
H^{\mathrm{f} 1}=H^{\mathrm{f} 0}+\Delta H^{\mathrm{f}} \\
H^{g 1}=H^{\mathrm{g} 0}+\Delta H^{g} \\
H^{p 1}=H^{\mathrm{p} 0}+\Delta H^{p}
\end{array}\right.
$$

In the formula, $H^{\mathrm{f} 0} 、 H^{80} 、 H^{\mathrm{p0}}$ are the heat consumption before and after the implementation of the time-sharing heat price; $H^{\mathrm{fl}} 、 H^{\mathrm{g} 1} 、 H^{\mathrm{pl}}$ are the heat consumption in the peak valley period after the implementation of the time-sharing heat price; $\Delta H^{\mathrm{f}}$ 、

$\Delta H^{\mathrm{g}} 、 \Delta H^{\mathrm{p}}$ are the heat change values before and after the implementation of the time-sharing heat price

Based on the theory of peak valley electricity price, we can try to introduce the electricity price elasticity matrix into the heat market, that is, the heat and heat price elasticity matrix.

The elastic coefficient of the relationship between heat consumption of thermal load and price change is expressed as follows:

$$
\varepsilon^{=-} \frac{\Delta H}{H} \frac{\mathrm{q}}{\Delta q}
$$

In formula (2): and are the relative increments of heat $\mathrm{H}$ and heat price $\mathrm{q}$ respectively.

The load elastic coefficient of thermal demand response is divided into self elastic coefficient and cross elastic coefficient, which are expressed as follows:

$$
\begin{gathered}
\varepsilon_{\mathrm{ii}}=\frac{\Delta H_{i}}{H_{i}} \frac{q_{i}}{\Delta q_{i}} \\
\varepsilon_{\mathrm{ij}}=\frac{\Delta P_{i}}{P_{i}} \frac{q_{j}}{\Delta q_{\mathrm{j}}}
\end{gathered}
$$

In equations (3) and (4), represents the self elastic coefficient, represents the cross elastic coefficient, and I and $\mathrm{j}$ represent the I and $\mathrm{j}$ periods respectively.

According to the definition of self elastic coefficient and cross elasticity coefficient of thermal demand response elastic matrix, the heat price elasticity matrix e is obtained as follows: 


$$
E=\left[\begin{array}{cccc}
\varepsilon_{11} & \varepsilon_{12} & \cdots & \varepsilon_{1 n} \\
\varepsilon_{21} & \varepsilon_{22} & \cdots & \varepsilon_{2 n} \\
\vdots & \vdots & & \vdots \\
\varepsilon_{n 1} & \varepsilon_{n 2} & \cdots & \varepsilon_{n n}
\end{array}\right]
$$

For the price type demand response of thermal users, after the user response in $t$ period, the change of heat consumption power is as follows:

$$
\left[\begin{array}{c}
\frac{\Delta H_{1}}{H_{1}} \\
\frac{\Delta H_{2}}{H_{2}} \\
M \\
\frac{\Delta H_{\mathrm{t}}}{H_{t}}
\end{array}\right]=E\left[\begin{array}{c}
\frac{\Delta q_{1}}{q_{1}} \\
\frac{\Delta q_{2}}{q_{2}} \\
M \\
\frac{\Delta q_{\mathrm{t}}}{q_{t}}
\end{array}\right]
$$

\subsection{Modification of heat price elasticity matrix considering satisfaction of heating mode}

The user's satisfaction with thermal mode measures the change of user's thermal mode. The user is the most satisfied, and the satisfaction is 1 . However, after the implementation of the time-sharing heat price, the user is stimulated by the price and forms a new heat load curve.

In this paper, the user's satisfaction with heating mode is defined as:

$$
\mathrm{p}^{\prime}=\frac{\sum_{t=1}^{24}\left|f^{\prime}\left(H^{\prime}, t\right)-f(H, t)\right|}{\sum_{t=1}^{24} f(H, t)}
$$

In the formula, represents the heat consumption of users in the dispatching cycle in typical days after the implementation of time-sharing heat price, represents the heat consumption in $t$ period before the implementation of peak valley time-sharing heat price, and represents the heat consumption of the $\mathrm{R}$ period after the implementation of the peak valley time-sharing heat price, which is a function of the peak valley average periods. is the change amount of user's thermal behavior, which can indicate the dissatisfaction of user's heating mode. The larger the user's heat change variable is, the lower the user's satisfaction is, and $\mathrm{P}$ is the user's satisfaction.

In addition, the satisfaction degree of hot users is transformed into the price type demand response. Then formula (6) becomes:

$$
\left[\begin{array}{c}
\frac{\Delta H_{1}}{H_{1}} \\
\frac{\Delta H_{2}}{H_{2}} \\
M \\
\frac{\Delta H_{\mathrm{t}}}{H_{t}}
\end{array}\right]=\mathrm{p} * E\left[\begin{array}{c}
\frac{\Delta q_{1}}{q_{1}} \\
\frac{\Delta q_{2}}{q_{2}} \\
M \\
\frac{\Delta q_{\mathrm{t}}}{q_{t}}
\end{array}\right]
$$

According to the actual situation of an industrial park, one cogeneration unit for central heating in the industrial park has a unit capacity of $640 \mathrm{mw}$, the minimum output of CHP unit is $260 \mathrm{mw}$, and the maximum output is $640 \mathrm{mw}$. The heat price before peak valley time-sharing heat price is $=180$ yuan / ton, and the heat price of each period of peak valley average is the decision variable.Peak period: 11-20, normal period: 7-10; 13-14, 21-22, valley period: 23-6. The operation results are shown in Figure1、Table 2 and table 3. The peak valley difference, load rate, primary energy consumption cost and heat load limit before and after response are taken as the evaluation indexes of optimization effect.

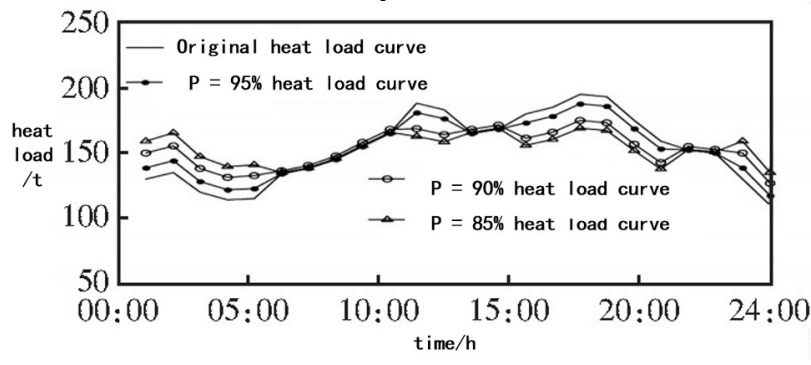

Figure 1. Heating load optimization curve of time-sharing heat price under different satisfaction constraints.

Table 2. Comparison of indexes before and after implementing peak valley heat price under different satisfaction constraints.

\begin{tabular}{ccccc}
$\begin{array}{c}\text { Operation } \\
\text { mode }\end{array}$ & $\begin{array}{c}\text { Peak } \\
\text { valley } \\
\text { difference }\end{array}$ & $\begin{array}{c}\text { Load } \\
\text { rate }\end{array}$ & $\begin{array}{c}\text { Heating } \\
\text { cost }\end{array}$ & $\begin{array}{c}\text { Heat } \\
\text { load } \\
\text { limit }\end{array}$ \\
\hline $\mathrm{P}=95 \%$ & 58.43 & 0.84 & 148.52 & 35 \\
$\mathrm{P}=90 \%$ & 47.98 & 0.88 & 142.63 & 10 \\
$\mathrm{P}=85 \%$ & 39.57 & 0.90 & 139.86 & 0 \\
\hline
\end{tabular}

Table 3. Optimal TOU price with different satisfaction constraints.

\begin{tabular}{cccc}
\hline $\begin{array}{c}\text { Time } \\
\text { period }\end{array}$ & Peak period & $\begin{array}{c}\text { Normal } \\
\text { period }\end{array}$ & $\begin{array}{c}\text { Valley } \\
\text { period }\end{array}$ \\
\hline $\mathrm{P}=95 \%$ & 216.84 & 187.17 & 136.53 \\
$\mathrm{P}=90 \%$ & 280 & 184.18 & 80 \\
$\mathrm{P}=85 \%$ & 388.84 & 182.35 & 63.23 \\
\hline
\end{tabular}

Analysis of simulation results, as shown in Figure 1, with the decrease of satisfaction, the heating load curve adjustment effect is better, the fluctuation is smaller, and the optimized heat load curve is more stable. In 0-6 valley period, with the decrease of satisfaction, the effect of heating load curve adjustment is better. During the peak period of 11-12 and 15-20, the heat consumption decreased with the decrease of satisfaction, which achieved the effect of peak shifting and valley filling.

Analysis of the data in Table 2 shows that with the decrease of customer satisfaction with the heating mode, the peak valley difference decreases, the load rate increases, the heating cost decreases, and the heat load limit decreases. This shows that different satisfaction has different optimal peak valley average heat prices, which 
provides the basis for the optimal heat prices under different satisfaction constraints.

From the analysis table 3, it can be seen that the optimal heat price in different periods of peak, valley and average is different for different heat users. Considering different satisfaction, it is more in line with the reality. The higher the user satisfaction is, the higher the heat price in valley and normal period will rise, the heat price in peak period will decrease, and the ratio of peak to valley heat price will increase with the decrease of satisfaction. This shows that the load side resources can be effectively mobilized to participate in the demand side by properly reducing the satisfaction of the load side in the heating system. With the decrease of satisfaction, users sacrifice their previous heat use habits, which can reduce the cost of heating.

To sum up, considering different heating methods has more practical reference value. The simulation results show that the optimal peak valley time-sharing optimal heat price is different under different satisfaction degree, which provides theoretical reference for different users to formulate peak valley heat price.

\section{Conclusion}

In this paper, the satisfaction degree of user's heating mode is defined, and the demand elasticity matrix of heating price considering the satisfaction degree of heating mode is modified. Based on this matrix, the time-sharing heat price is optimized, and the optimal peak valley time-sharing heat price with different heat consumption mode satisfaction is obtained, which provides theoretical reference for different heat users to implement time-sharing heat price. The simulation results show that under the mechanism of thermal demand response, the use of time-sharing heating price can effectively increase the scheduling flexibility of the system and reduce the investment cost. In the thermal market, economic means are used to encourage users to change the heat use mode, so as to achieve peak load shifting and valley filling, reduce heating cost, and achieve a win-win effect for both heating and heating users.

\section{References}

1. Shariatkhah $\mathrm{M}-\mathrm{H}$, Haghifam M-R, Mohesn P$\mathrm{M}$, et al . Modelling the reliability of multicarrier energy systems considering dynamic behavior of thermal loads[J] . Energy Build, 2015(103): 375-383 .

2. Hassine I B, Eicker U . Impact of load structure variation and solar thermal energy integration on an existing district heating network $[\mathrm{J}]$. Applied Thermal Engineering, 2013, 50(2) : 14371446 .

3. Federal Ministry for Economic Affairs and Energy. An electricity market for Germany's energy
transition[R]. Berlin:Federal Ministry for Economic Affairs and Energy, 2015.

4. Green J, Newman P. Citizen utilities: the emerging power paradigm. Energy Policy 2017;105:283-93.

5. Ran Liping. Review of cogeneration at home and abroad [J]. Science and technology information, 2009 (18): 327-327

6. Luo Baifeng, Mu Yunfei, He Wei, Yu Xiaodan, Wei Wei, Jia Hongjie, sun min. evaluation method of power supply capacity of electric gas coupling integrated energy system considering static security constraints [J]. Global energy Internet, 2019,2 (05): 433-440

7. Li Jinghua, Zuo Junjun, Wang Sai. Risk assessment and analysis of large scale wind power grid connected power system [J]. Power grid technology, 2016,40 (11): 3503-3513

8. Fang Shaofeng, Zhou Renjun, Xu Fulu, Feng Jian, Cheng Yuanlin, Li Bin. Optimal operation of integrated energy system of microgrid in the park considering the comprehensive demand response of various electric heating loads [J]. Journal of power system and automation, 2019 (online edition)

9. Wang Yangzhi, Zhou Renjun, Li Juan, Wang Yu, Chen Yi, Ren Qingqing. Two stage optimal dispatch of wind power thermal power plants with heat load regulation $[\mathrm{J}]$. Journal of power system and automation, 2019,31 (05): 13-20

10. Gu zepeng, Kang Chongqing, Chen Xinyu, Bai Jianhua, Cheng Lu. Operation optimization of electrothermal energy integration system considering heat supply network constraints and wind power consumption benefit analysis [J]. Chinese Journal of electrical engineering, 2015,35 (14): 3596-3604

11. Chen cangyang, $\mathrm{Hu}$ Bo, Xie Kaigui, et al. Peak valley time of use price model considering power system reliability and power purchase risk [J]. Power grid technology, 2014,38 (08): 2141-2148 